\title{
Management of intellectual capital held by Tanzania's higher learning institutions: Strategies and challenges
}

\begin{tabular}{|c|c|}
\hline \multicolumn{2}{|c|}{$\begin{array}{l}\text { Authors: } \\
\text { John J. Iwata }{ }^{1} \text { — } \\
\text { Ruth Hoskins }{ }^{1} \text { (] }\end{array}$} \\
\hline \multicolumn{2}{|c|}{$\begin{array}{l}\text { Affiliations: } \\
\text { 'Department of Information } \\
\text { Studies, College of } \\
\text { Humanities, University } \\
\text { of KwaZulu-Natal, } \\
\text { Pietermaritzburg, } \\
\text { South Africa }\end{array}$} \\
\hline \multicolumn{2}{|c|}{$\begin{array}{l}\text { Corresponding author: } \\
\text { John Iwata, } \\
\text { iwata2j@gmail.com }\end{array}$} \\
\hline \multicolumn{2}{|c|}{$\begin{array}{l}\text { Dates: } \\
\text { Received: } 06 \text { Sept. } 2019 \\
\text { Accepted: } 02 \text { Sept. } 2020 \\
\text { Published: } 30 \text { Nov. } 2020\end{array}$} \\
\hline \multicolumn{2}{|c|}{$\begin{array}{l}\text { How to cite this article: } \\
\text { Iwata, J.J. \& Hoskins, R., } \\
\text { 2020, 'Management of } \\
\text { intellectual capital held by } \\
\text { Tanzania's higher learning } \\
\text { institutions: Strategies and } \\
\text { challenges', South African } \\
\text { Journal of Information } \\
\text { Management 22(1), a1151. } \\
\text { https://doi.org/10.4102/ } \\
\text { sajim.v22i1.1151 }\end{array}$} \\
\hline \multicolumn{2}{|c|}{$\begin{array}{l}\text { Copyright: } \\
\text { (C) 2020. The Authors. } \\
\text { Licensee: AOSIS. This } \\
\text { is licensed under the } \\
\text { Creative Commons } \\
\text { Attribution License. }\end{array}$} \\
\hline \multicolumn{2}{|l|}{ Read online: } \\
\hline 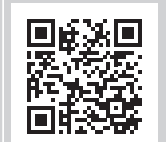 & $\begin{array}{l}\text { Scan this QR } \\
\text { code with your } \\
\text { smart phone or } \\
\text { mobile device } \\
\text { to read online. }\end{array}$ \\
\hline
\end{tabular}

Background: The economic well-being of any organisation in the world today significantly depends on the intellectual capital possessed by these institutions. However, with its richness in intellectual capital, some higher learning institutions in Tanzania are facing financial hardships.

Objectives: To establish methods used by Tanzania's higher learning institutions in managing the intellectual capital in their possession, with the focus of establishing a link between such practices and the financial performance of such institutions.

Methods: This study was conducted using a multiple case study design, employing a purely qualitative research approach. Purposive sampling technique was used to involve respondents in this study. Collected data were analysed using thematic content analysis.

Results: The visited institutions had a wide range of intellectual capital such as human, relational and structural capital. The intellectual capital found was managed using various methods, including careful recruitment of staff and knowledge-sharing strategies. Although the practices of managing some aspects of such capital were at a very basic level at the registry points, the practice was found to be very important for the economic well-being of the institution.

Conclusion: Tanzania's higher learning institutions possess a wide range of intellectual capital, and its management methods vary depending on the aspect of such capital. More importantly, the intellectual capital had a significant link with the financial performance of the institutions. However, the process of managing intellectual capital faced some challenges, including improper succession planning and the lack of a sharing culture.

Keywords: economic well-being; Tanzania; higher learning institutions; intellectual capital; intellectual capital management; knowledge management.

\section{Background}

The prerequisite for the functioning and development of any institution, including higher learning institutions, is its resources (human, physical and financial). However, in an economy where the only certainty is uncertainty, the one reliable source and resource for lasting competitive advantage is an organisation's intellectual capital (IC) (Nonaka 1998). Abdulaali (2018) agrees that IC consists of three components: human capital, structural capital (or organisational capital) and relational (customer) capital. In this context, therefore, the 'human capital' refers to the competences, experiences and value characteristics of an organisation's workforce that are in the minds of individuals. Such capital in a form of knowledgeable employees takes with them when they leave an organisation or a firm. The structural capital (also called organisational capital or internal capital) refers to the capital that is left or stays within organisations at the end of the working day or when employees leave the organisation. It includes information systems, databases, policies, intellectual property (IP) and culture. In other words, it is the knowledge embedded in organisational structures and processes. In contrast, the relational capital is also known as the customer capital or external capital that refers to all relations an organisation entertains with external subjects, such as customers, suppliers, partners, clients, brand names, trademarks and reputation. According to Roos, Bainbridge and Jacobsen (2001), this type of capital is what creates the wealth and competitive advantage of the organisation. Therefore, in its simpler form, IC is defined as the combination of all the intangible values and resources of an organisation, covering its people (human capital), the value relating to its relationships (relational capital) and everything that is left when the employees go home, retire or quit their jobs for any 
reason (structural capital) of which IP, intellectual assets and innovations are but the only components (Abdulaali 2018; Asiaei \& Joush 2015).

Therefore, management that entails creating, shaping and updating the stock of IC requires the formulation of a strategic vision, which blends together all three dimensions of IC within the organisational context through exploration, exploitation, measurement and disclosure. Roos et al. (2001), Asiaei and Joush (2015) and Abdulaali (2018) show that IC is also used in the context of assessing the wealth of organisations because such resources or values are the source of the tangible value (physical and financial assets) of the organisation including books, buildings and other physical assets and financial capital that together with the IC make up the real value and the economic status of the organisation.

It is a fact that the economic status of an organisation is measured by considering both the intangible and tangible assets of the organisation. However, Leaniz and Bosque (2013) and Abdulaali (2018) are of the view that IC offers a potential source for sustainable competitive advantage and is the source from which economic growth may sprout. This means that the IC possessed by an institution is the key and heart to the institutional development. Thus, it is the assumption of the authors of this article that IC can make other resources (physical and financial) available in the institution.

Zschockelt (2009) states that IC gained attention in the academic world as a result of the shift from a massproduction economy to a more knowledge-based economy, which highlights the creation, development and retention of knowledge by employees. Nonaka and Takeuchi (1995) and Nonaka (1998) are of the view that when markets shift, technologies proliferate, competitors multiply and products become obsolete almost overnight. Successful companies and organisations are those that consistently generate new knowledge, disseminate it widely throughout the organisation and quickly embody it in new technologies and products. Generally, these authors (Abdulaali 2018; Leaniz \& Bosque 2013; Nonaka 1998; Nonaka \& Takeuchi 1995) view the management of IC as an important strategy for an institution's survival and success. Hence, the higher learning institutions are urged to properly manage the IC in their possession. This is because the management of IC is important in simplifying the identification and mapping of and accessing to such intangible assets.

Management of IC informs the patterns of IC flow within institutions, making it easy to prioritise the vital ones and related crucial issues. These include catalysing and accelerating learning patterns, identifying best practices and disseminating these throughout the institution (Antosova \& Csikosova 2011; Pourkiani, Sheikhy \& Daroneh 2014). Moreover, it helps in the sound performance of the organisations specifically in the following functions: constantly supervising the value of assets and finding ways to increase organisational value, understanding social networks and identifying agents of change, increasing innovation, understanding how knowledge creates some reciprocity, increasing cooperation activities and a knowledge-sharing culture as a result of increased awareness of management benefits, increasing employees' self-perception and motivation and creating a performanceoriented culture (Antosova \& Csikosova 2011; Davenport \& Prusak 2000; Ding \& Li 2010; Pourkiani et al. 2014). Managing IC is also beneficial in increasing transparency, decreasing capital costs, rising stock prices, and simplification of marketing (Pourkiani et al. 2014). Pourkiani et al. (2014) and Abdulaali (2018) are of the view that management of IC should focus on growing the stock of an institution's IC in order to ensure the sustainability of its competitive advantage.

Zschockelt (2009), Leaniz and Bosque (2013) and Pourkiani et al. (2014) recognise IC as the main asset used in creating the superior financial performance of an institution. As higher learning institutions are rich in IC, they are expected to generate enough funds from selling the products generated from their available IC (Zschockelt 2009). The three elements of such capital found in higher learning institutions are the human capital that is in the form of skills or competences and know-how contained in the minds of employees, the relational capital that includes the brand names and reputation of the institution and the relationships with possible customers of the institution's products and the structural capital is what enable human capital to function, it consists of the supportive infrastructure, processes, and databases of the organisation that can be sold and bought.

It is from such a context that one would expect that regardless of the situation, higher learning institutions should not suffer from economic hardship because of the IC in their possession. Such institutions are in a good position to create future wealth and competitive advantage over other organisations. Hence, it was the assumption in this study that higher learning institutions, as knowledge-creating organisations, would continue striving, endeavouring even when other organisations experience economic hardship, because higher learning institutions possess a rich stock of the available IC. Therefore, the higher learning institutions will keep generating new knowledge and commodities and increasing continuous innovation from the accumulated IC (Zschockelt 2009).

As stated earlier, in today's economy, IC has been considered as a key factor for innovation and the new foundation for competition, as well as the primary driver of sustainable competitive advantage (Hamzah \& Ismail 2008). According to Marr (2008), the success and value creation of any organisation in today's economy are driven by IC. Marr (2008) urges that to positively impact the future success and value of organisations, higher learning institutions need to critically manage the IC that underpins value creation. This means that the economic well-being of higher learning institutions, including those available in Tanzania, significantly depends on the IC possessed by such institutions. 
However, for so long, higher learning institutions in Tanzania have been dependent on government budgets for their economic well-being (Abeli 2010). That is why the majority of them are facing several very similar challenges although they were supposed to be the engines of change and drivers of socioeconomic and technological development. Abeli (2010), citing the Basic Education Statistics in Tanzania (Ministry of Education and Vocational Training 2010), asserts that the lack of funds was amongst the challenges for institutional developments, which subsequently led to the dilapidation of institutional infrastructures. Using Tanzania's budget statistics from 2005, Abeli (2010) gives details that the country's annual budgets set aside for higher education for the past 5 years ranged between $21 \%$ and $26 \%$ of the total education budget, and that most universities received only about $20 \%-30 \%$ of what they normally request annually. Furthermore, Abeli (2010) is of the view that higher learning institutions are encouraged to generate more funding from other sources whilst the government is looking for the solution of this problem. Consequently, IC management is considered as a fundamental activity for institutional survival and development, as organisations have been demanding a top-notch IC management system to secure a competitive edge and a capacity for the core missions of higher learning institutions in terms of teaching, research and consultancy (Marr 2008; Mercier-Laurent 2014; Leaniz \& Bosque 2013).

\section{Statement of the problem}

Experience shows that the worth of any institution is assessed by the amount of IC it possesses. Therefore, IC in any institution needs a proper management for the sound and sustainable development of the institution. Otherwise, such institutions will experience financial hardship and high staff attrition rate on an annual basis (Abeli 2010). Abeli (2010) states that:
... at Sokoine University of Agriculture, over the past 20 years, the institution lost over 90 senior staff to other institutions whilst at the University of Dar es Salaam (UDSM), over 50 senior staff are on leave without pay. (p. 18)

This is also the situation at other universities in the country (including Moshi Co-operative University [MoCU] and Tumaini University Makumira [TUMA]). Leaniz and Bosque (2013), Mercier-Laurent (2014) and Abdulaali (2018) show that proper management of IC has an influence on the financial performance and independence of the organisation. These authors (Abdulaali 2018; Leaniz \& Bosque 2013; Mercier-Laurent 2014) observed that a metric for the value of IC has a direct impact on the financial well-being of the institution possessing such resources. This means that if the institution's IC is well managed, such a capital would allow the institution to acquire considerable money from selling knowledge products. These products may include the know-how to be sold through exposing the graduates to the labour market, providing consultancy services and innovations in a form of information systems, databases and IP rights.
According to Abeli (2010), financial constraints are the driver of attritions. It is in this context that, maybe, some of Tanzania's higher learning institutions experience financial hardships and high staff attrition rate as stated by Abeli (2010) because the institution's IC was not well managed to attract the financial performance of the institution. Hence, unimproved work environment and financial gains amongst employees could subsequently lead to staff attritions. More importantly, the financial performance of such institution needs proper marketing strategies to attract consumers to buy or continue using the knowledge-driven commodities produced by such institutions and in doing so improves the financial and economic well-being of the institution. Otherwise, the institutions should expect the continued financial hardship even if they possess a metric of the IC.

There is scant literature on this subject in Tanzania, particularly on the management of IC in higher learning institutions. Therefore, the current study adds to this gap by investigating the management of IC in Tanzania's higher learning institutions, with the aim of revealing ways to improve the financial performance of such institutions, of which most of them still face financial hardship instead of enjoying the financial performance accrued from the IC in their possessions. Also, this study aimed to reveal the ways in which the IC marketing strategies are managed by Tanzania's higher learning institutions.

\section{Objectives of the study}

The specific objectives of this study were to:

- determine the IC that is held by Tanzania's higher learning institutions

- determine methods under which the IC held by Tanzania's higher learning institutions is managed

- establish the link between the IC management practices and the economic well-being of the institutions

- establish challenges encountered by the higher learning institutions when managing IC.

\section{Theoretical framework}

This study was underpinned by Davenport and Prusak's (2000) Working Knowledge model. This model considers organisations (higher learning institutions in this case) as knowledge markets, comprising buyers, sellers and brokers. According to the model, markets work by having pricing and payment mechanisms. Thus, people with IC will take time and effort to share the resources they possess if they expect the favour to be returned or rewarded, by gaining a reputation either for owning IC or for being willing to share (Davenport \& Prusak 2000). The model considers information technology (IT) as one of the main factors that can positively affect sharing of IC. If wisely used, IT can help build marketplaces (both physical and virtual spaces) dedicated to IC exchange. Amongst many other factors mentioned in the model as affecting the sharing of IC is trust. According to the model, trust is the result of the well-defined norms and values that may also be reflected 
in the institution's vision and mission statements. In the context of this study, employees in higher learning institutions will share their IC with the people they trust. Thus, this makes it a responsibility of a higher learning institution to create trust between its staff members and stakeholders.

Moreover, the model advocates for the marketing of knowledge; however, it cautions regarding the observance of knowledge market signals, efficiencies and absence of pathologies. Knowledge market signals are about indicating the presence of knowledge in the organisation and the ways it can be accessed. In this context, this refers to the presence of an institutional knowledge grid. Efficiency of markets entails the timeliness of buyers and sellers readily meeting and exchanging goods (the IC). Additionally, the efficiency of markets depends on three factors, namely, completeness of information, the localness of knowledge and the reduction in asymmetry of knowledge in organisations to allow buyers and sellers to interact or meet (Davenport \& Prusak 2000).

When the model encourages absence of pathologies, this means that there should be no monopolies of knowledge by one person or group when others need it (Davenport \& Prusak 2000). The IC owners should be allowed to rent their expertise to solve financial problems, but they should not sell their expertise at a high price; they should allow competition to lead to a moderate price. This depends on the legal systems that exist. Therefore, if knowledge marketing is well organised, the institutions expect the following benefits: higher workforce morale, greater corporate coherence that involves IC owners in creating corporate goals and strategies, richer knowledge (IC) stock by bringing together people with different experiences and competencies to work on the same problem (including financial) and a stronger meritocracy of ideas (Davenport \& Prusak 2000). According to this model, any organisation wanting to excel in managing IC should accomplish the sub-processes of the following three knowledge management processes, namely, generation, codification and transfer. Consequently, this study focused on these three processes as they are the only criteria to ensure the productive management of IC. Therefore, the model is valuable for this study that falls under the pragmatism paradigm.

\section{Literature review}

In this era of a knowledge economy, the world is experiencing that the idea of managing IC attracts interest and increasing popularity in academia and in business environments (Mercier-Laurent 2014). This is because of the contribution it makes as a driver of value creation for the pursuit of competitive advantage recently recognised in modern competitive environments (Pourkiani et al. 2014). Antosova and Csikosova (2011), Mercier-Laurent (2014) and Pourkiani et al. (2014) are of the view that IC has superseded physical capital as the principal source of value that forms the basis of the successful development of companies and countries. Therefore, any organisation wishing to compete successfully in the newly emergent knowledge economy must attend to the task of growing its stocks of IC for obtaining competitive advantage.

Experience shows that this new era of technology, inventions and innovation has had a significant impact on the strategies, objectives and goals of many companies and organisations. The studies of Hamzah and Ismail (2008) and Ding and Li (2010) have shown that it is important to manage an organisation's IC as it comprises intellectual materials such as knowledge, information, IP, experience and competencies that employees in the institution own in their minds and that can be employed to create wealth and contribute to the institution's development. According to Hamzah and Ismail (2008), an organisation's IC must be managed for it to maintain its competitive edge. Furthermore, Mercier-Laurent (2014) believes that there is a right way of managing intangible wealth in connection with tangible aspects.

Regarding the approach to manage IC, Hamzah and Ismail (2008:241) state that 'so far, there is no general approach to manage intellectual capital which has been accepted... The choice depends on their priorities and capabilities'. Therefore, organisations are urged to begin managing their IC by defining its scope and its strategic vision. The organisation needs to focus on formulating a strategic vision for its IC and then define the scope of its IC management programme. According to Ding and Li (2010), IC management is divided into three layers: the core layer, the expansion layer and the strategy layer. The layers are detailed by Ding and Li (2010) as follows: in the core layer, knowledge management should provide the knowledge platform for the expansion of IC by assimilating exterior knowledge, integrating interior knowledge and creating new knowledge. In the expansion layer, the enterprise's IC could realise value enhancement by the expansion and accordingly drive the value enhancement of the whole enterprise. The strategy layer is a subsystem of the management of the enterprise; the management of the enterprise's IC must accord with the development strategy of the enterprise and make proper adjustment according to this strategy.

Looking at the economic status of higher learning institutions in Tanzania, Abeli (2010) opines that a majority of universities in developing countries have limited partnerships with business communities and low capacity to turn innovations into commercial products. According to Abeli (2010), universities are facing a number of challenges, including little investment and inadequate budgets set aside by governments to run them. Therefore, Abeli (2010) suggests that whilst the government is looking for the solution of this problem, universities are encouraged to generate funding and to compete for more funding from other sources.

Therefore, from the review of literature, the following has been observed: (1) there are limited studies on the management of IC conducted with the focus of establishing the link of such practices with economic well-being of 
higher learning institutions in Tanzania and (2) more importantly, few purely qualitative studies in Tanzania that establish the challenges encountered by higher learning institutions when managing IC have been conducted.

\section{Research methods and procedures}

This study was conducted by using a multiple case study design from two universities in Tanzania, namely, MoCU and TUMA, whereby a purely qualitative research approach guided the sampling process, data collection and analysis. The two universities involved in this study were purposefully selected. Whilst MoCU was sampled to represent public higher learning institutions, TUMA represented private institutions. As stated earlier, the rationale behind such selection was to establish the influence of ownership (public or private) in managing IC. The sample for the study consisted of three groups of leaders from the visited institutions. Each group of leaders was purposively selected as a result of the leadership positions they occupied within the institutions. The assumption was that because of their positions, they would be able to provide well-thought and evidence-based responses. Thus, the study included directors of human resources management and administration (DHRMAs) because this group of leaders dealt with identifying the shortage of and recruiting the required human capital within the institution. Deputy vice chancellors responsible for administration and finance (DVCAFs) participated as they oversaw all matters related to finances, marketing strategies and management of all the available intangible and tangible capitals within the organisation, and deputy vice chancellors responsible for academic affairs (DVCAAs) were included because they were responsible for overseeing the flow of knowledge within and outside the organisation. More importantly, the DVCAAs are the ones responsible for teaching, consultancy, research and innovation. In total, the study involved six respondents: two DHRMAs, two DVCAFs and two DVCAAs. Data were collected through semi-structured face-to-face interviews with all the mentioned participants. Direct observation was also used in cases where the institution had structural capital. Hence, the available storage places were observed for adequacy of preserving such capital.

The collected qualitative data were analysed using a thematic content analysis approach. This approach enabled the researcher to study collected statements in an indirect way through an analysis of the communication (Fraenkel \& Wallen 2003). The content of interviews was further broken down into the smallest meaningful units of information that helped in ascertaining values and attitudes of respondents. Prior to the conducting of this study, ethical clearance was sought from all the involved institutions.

\section{Results of the study}

The findings presented and discussed in this section are based on the face-to-face interviews conducted with selected leaders from MoCU and TUMA supplemented with observation of how the structural capital is managed.

\section{The intellectual capital held by higher learning institutions in Tanzania}

During data collection, the first question of the interview sought respondents' awareness of the range of IC owned by their institutions. Results show that the visited higher learning institutions had a wide range of IC with multidisciplinary specialisation ranging from 'human capital, relational capital to structural capital'. This response created a need for respondents' knowledge regarding the availability of each of the mentioned capitals. Thus, respondents were asked to clearly state the availability of each aspect of capital and discuss how each has contributed to the institutional development. The results indicated that respondents were of the view that in terms of 'human capital', their institutions had personnel with adequate skills and competences in the diversified fields of specialisation as per the institution's focus and value characteristics. According to these respondents, the available human capital has been performing all the core activities of their institutions, including conducting training and teaching sessions, researching and provision of professional advice to needy individuals or organisations. Whilst one respondent had this to state:

'This uses various strategies to acquire and retain IC for the future development of the university. Although retaining staff has been very challenging, but as for now the University has many people with diversified areas of expertise as per the university vision and objectives. Thus, we haven't stopped to perform our core activities, such as teaching, researching and conducting consultancy services.' (Participant 1, DVCAA, 13 January 2017)

\section{Another respondent stated that:}

\begin{abstract}
'Our university achievement and development (in terms of the buildings and the increased number of students enrolment) that you see today as compared to five years back is because we have enough human capital to perform all the university's core functions. This provides an evidence that our university has invested much in human capital through education and training aiming at improving levels of quality of teachers and pedagogical tools, and the quality of the university products (graduates).' (Participant 3, DHRMA, 13 January 2017)
\end{abstract}

In terms of 'relational capital', the respondents were proud of having a good relationship with the community, students and possible employers, including financial companies, cooperative societies and schools. As one of the respondents stated:

'In terms of the relational capital we have good relational capital, maybe [it] is due to our reputation in teaching and researching in the areas of our specialisation. We are having good relationships with students and the community where these students are both local and international. And we are really serious in maintaining such relationships. Also, we are very proud that we have a good relationship with government that has been the main employer of our graduates. This good relationship with our customers and government is what made us active till now.' (Participant 4, DVCAA, 17 January 2017) 
This was also supported by a respondent from another university who affirmed that:

'Our university has a very good relationship $[s]$ with co-operatives and financial institutions. Some of the financial institutions and co-operatives have been hosting our students for their practical training and later on they do employ them.' (Participant 2, DVCAF, 11 January 2017)

Also, 'structural capital' respondents from all of the visited institutions were of the view that very little was in their possession. Under this aspect, the respondents frequently mentioned availability of websites, policies and books authored by the employees of the institutions as the only structural capital available. When another respondent was asked to state whether his institution had patents or any IP rights of all innovative works by the employees of the institution, which include text about the techniques, procedures and programmes, diagrams, software, information systems, data and databases that enhance the delivery of goods and services, the following response was obtained:

'To be honest, maybe we are behind on that understanding. We haven't succeeded that much on that area, only that a very few as I have mentioned the websites, institutional policies and books written by our staff are in our possession.' (Participant 3, DHRMA, 13 January 2017)

Another respondent stated that:

'Our university does not own copyright or patent of innovation made by the university staff. However, the university implements the policy that any staff [at any level] who publish his or her work of mind is supposed to submit one copy to the library. The copyright or any other intellectual property rights of such work does not belong to the university, rather [it is] the author's property.' (Participant 1, DVCAA, 13 January 2017)

Providing experiences at his university, one respondent stated that:
'This is new understanding, our university has no policy on the management of structural capital, only the common understanding that university policy documents and guidelines bear the copyright to the university. I had no knowledge before this interview that infrastructure, processes, databases, methods, procedures and methodologies are invented by staff during his or her term of employment to enable human resources to function. Now I am aware that any innovation in a form of patents, copyrights and trademarks are embedded and owned by the institutions owning the employee who come out with a particular innovation, and that such capital should remain with an institution even when the employee leave the job.' (Participant 5, DVCAF, 17 January 2017)

The findings indicate that the visited institutions had a wide range of IC and that respondents were aware and very certain about the availability of the human and relational capitals than the structural capital. The results show that all respondents were very sure about the contribution of human and relational capital to the development and continued existence of the institution. However, for the structural capital, only copies of books and policies authored by the institutional employees were shown. Considering the state of insufficient utilisation of the structural capital, respondents requested training on awareness creation on the ways institutions can track and capture such capital and utilise it for the economic well-being of the institution. Whilst one of the senior respondents observed that:

'This interview has been very educative and interesting to me. I really see the need of having workshop on this topic (the IC and its management) to create awareness to all departments on how the IC can be beneficial to both of the parties (individual owners and the institution). I think that a series of training workshops and seminars will enable the university realise the benefits of properly managing all forms of IC in their possession.' (Participant 2, DVCAF, 11 January 2017)

The observation was also supported by another respondent who stated that:

'This conversation has been an eye opener to me. It is high time now our university should start to organise regular training on IC management to enable employees understand the value and benefits of the available IC at our university. Adequate and formal training on the management of IC would help the university to come out with the proper mechanism to capture and take advantage of the available IC in the development and operation of the university.' (Participant 6, DHRMA, 17 January 2017)

Therefore, whilst IC was found to be available within the visited institutions, the findings also established the need for institutions to have proper mechanism for capturing the structural capital. This is because the structural capital is a special and critical element of IC, and hence it needs to be captured and institutionalised in an organisation.

\section{Managing intellectual capital in higher learning institutions}

This study sought to obtain institutional leaders' views on the strategies and methods used by higher learning institutions in managing the IC in their possessions. The results show that respondents held the view that there are various methods and strategies used in managing IC. The varied methods and strategies are based on the aspect of the IC (i.e. human, relational and structural capitals) itself. The focal management processes included the acquisition, organisation and storage and transfer.

\section{Acquisition and retention of intellectual capital}

Respondents were asked to identify the means through which their institution acquired the IC in their possession. The responses showed that various strategies and methods related to the acquisition and retention of quality and experienced human capital (employees) were used. The strategies included careful recruitment of new staff with expertise and required experiences in some areas of professionalism. Whilst one respondent stated that:

'As a public institution, our IC are acquired through public procurement procedures. Then the human capital, particularly the employed personnel, are required to enrich their know-how through career development programmes [where the employees are required at their different levels] to excel their knowledge in the 
fields of their specialisation by attending further studies, involving themselves in teaching-learning, and conducting research projects.' (Participant 3, DHRMA, 13 January 2017)

Another respondent made this statement:

'Our university uses various strategies to retain its employees. The strategies include having various programmes to keep employees motivated and focused on the university's and own goals so that they choose to remain employed and fully productive for the benefit of the institution.' (Participant 5, DVCAF, 17 January 2017)

Based on Abeli's (2010) observation, higher learning institutions experienced attrition from retirements or other reason(s). To establish the institutional readiness and preparedness to respond to such a situation, respondents were asked to state their views on such a situation at their institutions. A respondent from MoCU held this view:

'For the case of retirement, our institution has a system of providing contract employment to the experienced retired officers in request to the government permission; and that for the purposes of retaining their know-how to the institution, these officers are allocated with junior staff for mentorship programmes and are encouraged to conduct a series of seminars in the areas of their specialisation.' (Participant 1, DVCAA, 13 January 2017)

Another respondent stated that:

'... this university has a culture of running departmental academic meetings where employees exchange their know-how on various matters.' (Participant 1, DVCAA, 13 January 2017)

Stressing on the importance of departmental knowledgesharing sessions, another participant opined that:

'For sure, departmental or inter-departmental sharing of IC is very important; therefore, departments are urged to facilitate IC-sharing sessions and activities within the organisation through meetings, training, conferences and workshops. Although that has not been the practice in our institution, I really urge our departments to conduct the informal sessions where employees can share, refine and adopt ideas. Thus, once adopted, the ideas become institutional IC because employees act on it for the benefit of the organisation.' (Participant 6, DHRMA, 17 January 2017)

\section{Another participant had these views:}

'Our institution appreciates the role of knowledge-sharing in the management of the available institution's IC. Hence, as part of the university's top management; we have been encouraging our academic community to share what they know by holding meetings, training sessions and the use of technology.' (Participant 4, DVCAA, 17 January 2017)

The findings of this study indicate that most of the respondents were of the view that their institutions had their own mechanism to retain their staff and their know-how. The results show that the human capital in the visited institutions was acquired through employing new experts and training them by providing contracts after their retirement. To retain, the know-how employees' culture of sharing knowledge amongst themselves was used as a strategy. This simply means that the know-how was sometimes generated and shared through seminar sessions, meetings, workshops and conferences.

\section{Organisation and storage intellectual capital}

Questions for this section aimed at obtaining respondents' views on the ways in which institutions facilitated access to and retrieval of the IC (specifically the human and structural capitals) in their possession by the persons requiring the IC. Respondents were asked to state the ways in which their institution's IC was organised. Thus, prior to the main questions for this section, the researchers wanted to know whether the institutions had a knowledge grid (a map showing concentration and asymmetry of the available IC). The results showed that most of the respondents had the view that their institutions had nothing like a knowledge grid, whereas only one respondent stated that his institution had it. Respondents who indicated that they did not have a knowledge grid in their institutions were further asked to state how their institutional IC was organised. Responses showed that it was difficult for their institution to map the human capital in their possessions, but the structural capital such as books and policies was stored in the institution's library and some at the registry. One of the respondents stated that:

'It is a good idea to organise all aspects of IC in a grid of knowledge. The current practice is organising copies of books and journals produced by university academic community in the library, and their educational certificates at the registry point.' (Participant 2, DVCAF, 11 January 2017)

\section{Another respondent stated that:}

\begin{abstract}
'Our university does not have a knowledge grid, but as for this understanding, it is high time now for the university to introduce mechanism to manage all aspects of the IC including intellectual property as the means to getting prepared for staff attrition. The institution must be prepared to lose talent especially if they have the opportunity to move into their dream job or for greener pastures. To us this has been very challenging for the development of our university.' (Participant 5, DVCAF, 17 January 2017)
\end{abstract}

Although most respondents affirmed that their institutions had not done much to keep such capital safe, still they urged their institution to come up with proper mechanisms to collect and protect structural capital, including IP rights of all works by employees of the institutions.

The follow-up question to the respondent who responded that his institution had a knowledge grid was how much cost was incurred in establishing the grid. The response was that it did not cost anything. He stated that:

'... it costed us nothing [than just] requesting employees submit their educational certificates to the registry for keeping such records.' (Participant 3, DHRMA, 13 January 2017)

This prompted the researcher to conclude that nothing was in place as an institutional knowledge map because even when he asked to see it, the respondent failed to provide such help. 
Irrespective of the responses on the availability of knowledge grid, the researcher posed another question to know the value respondents attached to the knowledge grid. Results show that all respondents indicated that a knowledge grid (specifically the structural and human capitals) would be of great importance for the economic well-being of the institution and as a tool for marketing and coordinating the institution's IC. One of the respondents specifically had this view:

'Although in our institution we don't have such a thing, but I think having it in place is very important. I see it as very useful, especially in our institution where the IC is scattered. I think the grid of IC would help in coordinating utilisation and sharing of IC through various projects and programmes including providing solutions to the existing problems.' (Participant 3, DHRMA, 13 January 2017)

Another respondent stated that:

'I see the availability of the knowledge grid provides a platform whereby the University and prospective users (customers) of the University products can effectively capture, publish, share and manage the IC.' (Participant 1, DVCAA, 13 January 2017)

On the management of the relational capital, respondents had the view that their institutions had for a while now maintained a good relationship with the students and other education stakeholders by ensuring the institution provides a quality competence-based education. To supplement this, one of the respondents stated that:

'We are now in the process of conducting a tracer study to assessing and documenting about what the consumers of our products say about the strengths and weaknesses of our products (graduates) for improvement.' (Participant 2, DVCAF, 11 January 2017)

Another respondent suggested that:

'Keeping and maintain this good relationship with our stakeholders in this competitive era our institutions need to develop policies for creating and maintaining good communication and relationships with the identified stakeholders.' (Participant 6, DHRMA, 17 January 2017)

Moreover, after having recognised that amongst the visited institutions, there were no proper systems for managing IC, the researcher wanted the respondents to state the alternative methods and means by which their institution organised the available IC. The responses revealed that the visited institutions organised their IC resources mostly through ordinary filing systems at a very basic level at the registry points using basic organisational techniques such as folders. One of the respondents stated that:

'Everything is organised in our databases at the registry office. Also, computers in a form of folders are used for storing the institution's IC. Each employee has its personal file where information related to his or her competencies are stored. The registry professionals know how they classify and arrange files because there is where the IC is stored.' (Participant 3, DHRMA, 13 January 2017)
In the same institution, another respondent was of the view that:

'... this institution had no specific system to organise the available IC.' (Participant 1, DVCAA, 13 January 2017)

However, the respondent acknowledged that the institution should rectify the situation to ensure that there are specific personnel and a place or office responsible for organising, storing, utilising and adding new information to the available IC. This also was affirmed by one of the respondents who stated that:

'... this institution is supposed to have a proper system to organise the available institutional IC, but it is unfortunate that we do not have it.' (Participant 2, DVCAF, 11 January 2017)

All these responses indicate that in the two visited institutions, IC was not well organised to simplify its access, retrieval and marketing. Furthermore, it was observed that the practices of managing IC in these institutions were done at a very basic level at the registry points. A question was asked for respondents to substantiate if there was a specific person responsible for the management of IC at each of the visited institutions. The responses showed that none had such a position for IC management (i.e. no one was employed as the IC manager). Whilst one of the respondents from MoCU stated that:

'In our university's scheme of work, we do not have a position of such officer. Thus, we do not have a specific person specifically responsible for managing the IC. However, I think we should have one, whose responsibilities are to ensure that the available IC from all departments is well managed.' (Participant 1, DVCAA, 13 January 2017)

A respondent from one of the visited universities made this observation:

'... this university don't have that person; however, the activity to oversee all academic and knowledge-related matters is under the office of Deputy Vice-Chancellor responsible for Academic Affairs (DVCAA).' (Participant 1, DVCAA, 13 January 2017)

This is an important observation as it shows that although there was no individual employed to the position of Chief IC Management Officer, it does not mean that IC is not managed or there is no one responsible for the management of IC. However, this does not remove the truth that there were some failures in managing the IC amongst the visited institutions.

\section{Marketing of the intellectual capital held by the institution}

Respondents were asked to state whether there were any strategies that each institution had implemented to facilitate marketing of its IC. The responses showed that participation and collaboration at local and international conferences, seminars and exhibitions were the main strategies for marketing and promoting institutional IC, specifically the human and structural capitals. This means that whilst members of the institution in such forums were amongst the 
facilitators or participants but also through book exhibitions their works were available to other people. One respondent had this observation:

'As a growing university with strategies to market and promote our IC in various specialisations, we are now signing various memoranda of understandings with several institutions from within and outside the country as the means to market and promote our institutional IC.' (Participant 1, DVCAA, 13 January 2017)

\section{Another respondent had this view:}

'It is true that our University needs a proper marketing strategy to market the available IC. Such strategy should consider marketing as a tool to manage and retain the available resources while attracting prospective customers and/or motivating the current ones. Thus, our University has been using TCU exhibition and other academia fora as platforms to market the available IC. I also see the need to start using technology including the social media, mass media and media sessions, and write-ups as an effective and proper strategy for marketing the institutional IC.' (Participant 2, DVCAF, 11 January 2017)

\section{Economic benefit accrued from managing institutional intellectual capital}

To establish a link between the IC management practices and the economic well-being of the institutions, the respondents were asked to state the benefits accrued from managing the IC. The responses revealed that the wellmanaged IC had a positive influence on the economic wellbeing of the institution. Furthermore, the findings of this study revealed that IC (specifically the human and relational capitals) has been the main source of the financial performance of the visited institutions, as one of the respondents stated that the increased number of students that this institution has is because of the available human and relational capitals'. The findings serve as evidence to the conclusion that IC had impact on the financial performance of the institution because they attracted communities and students who pay for services (teaching and consultancy). A follow-up question to establish respondents' perceptions on the prime beneficiaries of a well-managed IC was asked. The responses showed that the prime beneficiaries included institutions and the community at large and individuals in the institution who owned such IC. One of the respondents had this view:

'The well-managed IC is beneficial first to the person owning such capital, and to the institution possessing the IC as well. This is because the individual owners normally use such capital for their day-to-day developments while the institution uses such knowledge for both social and economic benefit of their organisations.' (Participant 6, DHRMA, 17 January 2017)

The same respondent further stated that:

'On the other hand, for the community outside the institutions, the well-managed IC as resource is diffused to them through research, innovation and consultancies. Thus, the well-managed IC is very beneficial, as they influence social changes and practices for development.' (Participant 6, DHRMA, 17 January 2017)
Another respondent provided the view that:

'Out of economic gains, the management of institutional IC is very beneficial as it increases transparency within the institution, decreases capital cost for hiring experts from outside, and make[s] it easy to market the available institution's IC.' (Participant 1, DVCAA, 13 January 2017)

The respondents were also asked to state the main sources of the institution's income. The aim was to see whether the IC owned by the institution was considered as amongst the sources of income. Responses from all the six respondents showed that the main sources of income in higher learning institutions were students' tuition fees, government funding, international organisations' funds, consultancy activities and church offerings. One of the respondents at TUMA had the following statement:

'... apart from students' fee and church offerings, our university has another source of income which include consultancy fee, funded research and other related international collaborations.' (Participant 5, DVCAF, 17 January 2017)

Another respondent had this view:

'Our University's incomes are mainly from the government budget. Also, students' tuition fee, research grants and consultancy fee are among the sources of income of our University. On the other hand, the University has not gone far in utilizing the structural capital in a form of innovation and intellectual property rights for the betterment of the University.' (Participant 2, DVCAF, 11 January 2017)

Therefore, these findings show that the visited universities did not make full utilisation of the IC in their possession for the economic well-being of the university. The income of the visited universities depended on the government budget, if not on the diocese's offerings, as well as students' tuition fees, consultancy services and research grants from various funders. None were mentioned from structural capital (innovation and IP rights). This may also be amongst the reasons behind the increased financial hardships amongst higher learning institutions in Tanzania. Hence, the findings of this study provide a clear evidence for the importance of managing IC in higher learning institutions in Tanzania. This is because the IC is considered as a key factor for innovation; it is the new foundation of competition and the primary driver of sustainable competitive advantage (Leaniz \& Bosque 2013; Zschockelt 2009). As higher learning institutions are rich in IC, it is obvious that the community would expect them to generate enough funds from selling the products created from their available IC; however, unfortunately, little has been done in this regard.

\section{Challenges facing higher learning institutions in managing intellectual capital}

Respondents were then asked to explain the challenges associated with managing IC in their institutions. Their responses revealed that improper succession planning because of poor employment planning was one of the 
challenges. Urging the universities to rethink their IC management strategy, one of the respondents had this view:

'As a higher learning institution, we have proper ways of identifying and acquiring the IC for the organisation; however, I would rather urge our institutions to map the available intellectual capital, and set up the proper mechanism and criteria to measuring intellectual capital and reporting it in every year.' (Participant 5, DVCAF, 17 January 2017)

Moreover, the lack of a culture of exchanging, sharing and transferring IC within the institution constrained free flow of such capital within the organisation. This contention is in line with one of the respondents who affirmed that:

'You know, organisational culture may favour or hinder one or all aspects of managing IC. For example, in our institution we are having a big challenge on the aspects of sharing the available IC. The university has even decided to hire the retired experts on contractual bases, but we do not have formal forums and procedures to make sure the IC we need to retain to our university is well shared.' (Participant 1, DVCAA, 13 January 2017)

That respondent continued by asserting that:

'Maybe this is because in our institution, the available IC experience low level of competitiveness for personal and institutional income generation, thus owners and institutions (knowledge officers) have failed to translate their IC into monetary assets.' (Participant 1, DVCAA, 13 January 2017)

Another respondent stated that ' $[m]$ anagement of IC might thrive more in a flat structure where knowledge flows in all directions, both horizontal and vertical'. However, most of the respondents in this study opined a lack of trust as the main challenge in managing IC within their institutions.

In contrast, the respondents mentioned various perceived challenges in marketing IC, including the lack of personnel to market the available institutional IC, using IT facilities and applications, and competition in the market because of the increased use of science and technology.

\section{Ethical consideration}

This article followed all ethical standards for a research without direct contact with human or animal subjects.

\section{Discussion}

The findings of this study have highlighted three types of IC possessed by the higher learning institutions in Tanzania and some of the methods and strategies used in managing such types of IC. Using a sample of two higher learning institutions in Tanzania (MoCU and TUMA), the study showed that the higher learning institutions possessed a wide range of ICs, specifically the human capital, relational capital and structural capital. Also, the findings of this study showed that the higher learning institutions applied various methods and strategies in managing the IC in their possessions. The varied methods and strategies depended on the variation of the management processes. For acquisition and retention purposes, strategies such as careful recruitment of new staff with expertise and the required experiences, extension of the employment contract for retired officers, the use of academic meetings, facilitation of employees' culture of sharing knowledge through seminars sessions, workshops and conferences were used. Although there were no proper mechanisms to collect, organise and store the IC, the ordinary filing systems at the registry points were used. Moreover, the activity to oversee all academic and knowledge-related matters was under the office of DVCAA. This means that the institutions had various means of managing IC in their possessions.

The study also aimed at establishing strategies used by the visited institutions in marketing and promoting the institutional IC. The results showed that amongst the used strategies were the employees' participation and collaboration at conferences, seminars and exhibitions, use of mass media and media sessions and write-ups. However, some of the marketing challenges experienced by institutions included intensive use of IT facilities and applications and increased competition amongst certain popular staff at the institutions. It is the researchers' observation that the institutions should utilise the expertise of the popular staff, utilise IT to build marketplaces and create an institutional IC grid (both physical and virtual spaces) dedicated to IC exchange (Davenport \& Prusak 2000). This is what Nonaka and Takeuchi (1995) and Nonaka (1998) admit that when markets shift, technologies proliferate, competitors multiply and products become obsolete almost overnight. Thus, according to Nonaka and Takeuchi (1995) and Nonaka (1998), the successful organisations are those organisations that consistently generate new knowledge, disseminate it widely and embody it quickly in new technologies and products.

The findings of this study revealed that IC (specifically human and relational capitals) has been the main source of the financial performance amongst the visited institutions. Accordingly, it is important that higher learning institutions utilise the cost-effective strategy in marketing and promoting the available IC, both locally and internationally. This requires also the formulation of a strategic vision, which blends together all the three components of organisational IC. The vision should be effectively focusing issues on creating, shaping, updating and marketing of the IC stock, measurement and disclosure. Otherwise, the management of the IC held by higher learning institutions will be difficult. Hence, the financial hardship of the institutions may persist as well as the continued dependence on the government's budget for the institutions' operation.

Generally, various factors have been mentioned as the reasons constraining the management of IC. Such reasons included a lack of organisational sharing culture, lack of trust amongst employees in institutions, lack of time and meeting places and rewards going to the IC owners (Davenport \& Prusak 2000). Although limited partnerships with business communities and low capacity to turn innovations into 
commercial products were not mentioned as amongst the challenges constraining proper management of IC, Abeli (2010) observes that a majority of universities in developing countries including Tanzania face such challenge. Therefore, Abeli (2010) urges universities to establish partnerships with business communities as an IC marketing strategy and increasing the possibility of turning innovations into commercial products. According to Abeli (2010), turning innovations into commercial products is of great importance for the higher learning institutions to harness benefits from their IC.

\section{Summary, conclusion and recommendations}

This study adds value to the existing knowledge base by investigating the management of IC in Tanzania's higher learning institutions. The focus was on the link between such practices and the financial performance of such institutions. The findings of the study prompt conclusions that Tanzania's higher learning institutions possessed a wide range of IC comprising human, relational and structural capitals. Such institutions employed various methods for managing the IC in their possessions, including recruiting new employees with required expertise and sharing of the acquired IC. It was also found that the management of IC had a significant positive impact on the financial performance of both institutions and individuals possessing such capital. Also, the higher learning institutions in Tanzania faced some challenges in managing and translating the IC in their possessions into monetary value for the economic well-being of their institutions. Furthermore, although this study found that there were no persons employed as knowledge managers to oversee and ensure all activities related to managing IC and marketing of such capital, these activities were vested in the office of the DVCAA. Thus, it is from the findings of this study that various recommendations have also been provided to establish grounds upon which higher learning institutions could manage and market the IC in their possession for improving the economic well-being of such institutions. Here are the recommendations:

- Higher learning institutions should ensure that the available managers are trained and equipped with effective and formal strategies, skills and methods of managing (including sharing and developing) the available IC. Importantly, the five key steps to be followed by organisations for successfully managing IC as proposed by Marr (2008) should be regarded as modules of the training. The steps are: (1) identifying IC in the organisation, (2) mapping the IC value drivers, (3) measuring IC, (4) managing IC and (5) reporting IC. In addition, there should be a knowledge grid (proper database) to map and store the available IC assets for easy access, organisation and retrieval. Furthermore, universities should cultivate a knowledge-sharing and learning culture.

- Individuals in the universities should be influenced to develop a sense of willingness to share their knowledge with others and to learn from others on their own initiative. The actions and efforts of knowledge sharing should be measured and rewarded. Also, universities should appoint a specific person to a position of Chief Knowledge Officer to manage the knowledge of the institution; promoting the available IC should be the best strategy to ensure that the available IC is used for economic gains at the institution.

- Individuals and institutions should keep in mind that information technology is a proper tool to facilitate the management of knowledge in the world today. Therefore, there is a need to utilise it fully to perform all the management processes, simplify the IC access and retrieval, and marketing. Furthermore, IT should be utilised in order to make the IC easy for the person in need to retrieve or to locate the person possessing the special expertise.

\section{Suggestions for further studies}

There is a need to conduct a broader study covering almost all the higher learning institutions in Tanzania. Also, there is a need to conduct a study measuring the actual IC management benefits and impacts on the performance of higher learning institutions.

\section{Acknowledgements}

This article reports on the findings of the study conducted at Moshi Co-operative University and Tumaini University Makumira in Tanzania. Data for this study was collected during the Postdoctoral scholarship of the University of KwaZulu-Natal, South Africa in year 2016-2017.

\section{Competing interests}

The authors have declared that no competing interest exists.

\section{Authors' contributions}

All authors contributed equally to this work.

\section{Funding information}

This research received no specific grant from any funding agency in the public, commercial or not-for-profit sectors.

\section{Data availability statement}

Data sharing is not applicable to this article as no new data were created or analysed in this study.

\section{Disclaimer}

The views and opinions expressed in this article are those of the authors and do not necessarily reflect the official policy or position of any affiliated agency of the authors.

\section{References}

Abdulaali, A.R., 2018, 'The impact of intellectual capital on business organisation', Academy of Accounting and Financial Studies Journal 22(6) 1-16, viewed 23 February 2020, from https://www.abacademies.org/articles/the-impact-ofintellectual-capital-on-business-organisation-7630.html 
Abeli, W.S., 2010, 'Higher education and development: A critical nexus', Key paper presented to SARUA Workshop on Investment in Higher Education for Development: New directions, August 2010, University of Dar es Salaam, Tanzania,
viewed 14 September 2016, from https://www.sarua.org/files/Events/HE\%20 Finance\%201CT\%20Event/Presentation_Abeli_Paper.pdf

Antosova, M. \& Csikosova, A., 2011, 'Intellectual capital in context of knowledge management', in P. Pachura (eds.), The economic geography of globalization, pp. 113-142, viewed 10 August 2016, from http://cdn.intechopen.com/pdfswm/16921.pdf

Asiaei, K. \& Jusoh, R., 2015, 'A multidimensional view of intellectual capital: The impact on organisational performance', Management Decision 53(3), 668-697. https://doi.org/10.1108/MD-05-2014-0300

Davenport, T.H. \& Prusak, L., 2000, Working knowledge: How organisations manage what they know, Harvard Business School Press, Boston, MA.

Ding, Y. \& Li, G., 2010, 'Study on the management of intellectual capital', International Journal of Business and Management 5(2), 213-216, viewed 21 February 2016, from http://www.ccsenet.org/journal/index.php/ijbm/article/viewFile/5088/4250.

Fraenkel, J.R. \& Wallen, N.E., 2003, How to design and evaluate research in education, McGraw-Hill, Boston, MA

Hamzah, N. \& Ismail, M.N., 2008, 'The importance of intellectual capital management in the knowledge-based economy', Contemporary Management Research 4(3) 237-262. https://doi.org/10.7903/cmr.1045

Leaniz, P.M. \& Bosque, I.R., 2013, 'Intellectual capital and relational capital: The role of sustainability in developing corporate reputation', Intangible Capital 9(1) 262-280. https://doi.org/10.3926/ic.378

Marr, B., 2008, 'Impacting future value: How to manage your intellectual capital', Management Accounting Guideline (MAG), CMA, AICPA, and CIMA viewed 11 September 2016, from http://www.cimaglobal.com/Documents/ ImportedDocuments/tech mag impacting future value may08.pdf
Mercier-Laurent, E., 2014, 'Managing intellectual capital in knowledge economy' Position papers of the 2014 Federated Conference on Computer Science and Information Systems, pp. 253-257, viewed 19 July 2016, from https://fedcsis.org/ proceedings/2014/pliks/476.pdf

Ministry of Education and Vocational Training, 2010, Basic education statistics in Tanzania (BEST), 2006-2010 national data, United Republic of Tanzania, Dar es Salaam.

Nonaka, I., 1998, The knowledge-creating company, Harvard Business Review, Boston, MA.

Nonaka, I. \& Takeuchi, T.H., 1995, The knowledge-creating company: How Japanese companies create the dynamics of innovation, Oxford University Press, New York, NY.

Pourkiani, M., Sheikhy, A. \& Daroneh, M.S., 2014, 'Importance and status of intellectual capital in knowledge economy', Indian Journal of Fundamental and Applied Life Sciences 4(4), 512-518, viewed 23 October 2016, from http:// www.cibtech.org/sp.ed/jls/2014/04/JLS-062-S4-065-DARONEHIMPORTANCE.pdf

Roos, G., Bainbridge, A. \& Jacobsen, K., 2001, 'Intellectual capital analysis as a strategic tool', Strategy and Leadership, 29(4), 21-26, viewed 20 October 2016, from http://citeseerx.ist.psu.edu/viewdoc/download?doi=10.1.1.199.7546\&rep=rep1 \&type $=p d f$

Ulrich, W., 1988, 'System thinking, system practice, and practical philosophy: A program for research', System Practice 1(2), 137-163. https://doi.org/10.1007/ BF01059855

Zschockelt, F., 2009, 'The importance of developing intellectual capital for innovative organisations: Contributions from a HRM perspective', Unpublished master's thesis, University of Twente, Enschede, viewed 13 October 2016, from http:// essay.utwente.nl/59963/1/MSc_Felix_Zschockelt.pdf 